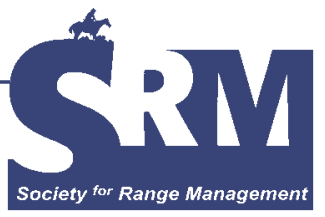

\title{
Recruiting Thoughts and Experiences
}

\section{Presentations about rangelands can be an effective way to better inform the public and attract students into college range programs.}

\section{By Jerry L. Holechek}

\section{Introduction}

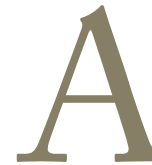

cross the western United States, student enrollment in college range science programs has been in a general downtrend for nearly 25 years. At New Mexico State University (NMSU), where I have taught range science classes for the past 27 years (since 1979), undergraduate enrollment in the range science program peaked in 1980 with about 85 students and steadily declined into the early 1990s, when it leveled off with 28 to 38 students depending on year. In spite of this relatively low number of undergraduate students, we managed to maintain the 6 range science teaching faculty we had at peak enrollment in 1980. However, times change. The advent of a new president at NMSU and other administrative changes in 2004 resulted in a hard look at the range science teaching faculty members relative to student numbers. The range science program was put under pressure to either increase undergraduate enrollment or reduce faculty. We began discussing various options to increase student numbers such as internet classes, off-campus classes, and actual recruiting in high school classrooms.

In my own case, after much thought as well as considerable encouragement from my department head, I decided that speaking to high school classes throughout New Mexico could be both interesting and productive. In the past I have strongly advocated improved information and education as a necessary way to build public support to conserve and improve rangelands. Although I have talked to many producers, college students, and conservation groups through the years, I had seldom talked to grade school or high school students or the public at large. I have now reached a point where the academic pressures to build teaching and research programs are behind me and my concerns are how to best finish my career and have a productive retirement. I reflect often on what a gratifying and enjoyable career choice range science has been for me. I still remain highly enthusiastic about the possibilities and opportunities that lie ahead for those who are in or entering my profession. Why not share my experiences and thoughts with young people who are trying to decide their career choice?

As this is written in February $2006 \mathrm{I}$ have now spoken to 30 different high school classes scattered throughout New Mexico. I have been surprised by both the lack of knowledge they have about rangelands and the level of interest they show in learning about them. In summary, I have felt my time and effort invested in speaking to high school classes was well spent.

My PowerPoint presentations evolved as I spoke to more classes. I still consider them a work in progress although I have been connecting well with the students. I will briefly discuss some of the key points of the approach I have found most effective.

\section{The PowerPoint Presentation}

I have learned it grabs attention and interest to start with 2 slides showing rangeland landscapes in high ecological condition showing livestock and wildlife in grassland and forest 
settings. I use these slides to explain and demonstrate what rangelands are and what modern range management is all about. I emphasize the concept of multiple use and the various products, including ecosystem services, that rangelands provide to society. I do point out that about $50 \%$ of the land area of the United States and 70\% of the land area of the world is classified as rangeland. From there I explain that the unique feature of range management is that it involves manipulating the grazing activities of large herbivores. I emphasize that we are first concerned with the protection and enhancement of soil and vegetation resources and next with maintaining and increasing the output of consumable range products for society such as red meat, wildlife, and water. The concept that rangeland is a renewable resource and about one-third of the annual production of forage plants can be safely removed is carefully explained. Next, I focus on describing the primary activities of range managers. I characterize these as 1) monitoring and surveys, 2) range improvements, 3) range management plans, 4) landscape planning and management, 5) dispute resolution, and 6) information and education. I use a variety of slides showing range professionals of different races, sexes, and age groups engaged in vegetation sampling, burning, fence construction, and computer analysis to illustrate these activities. In my next section I show some degraded landscapes invaded by brush and trees followed by slides illustrating what can be achieved with various range restoration practices. I express my own sense of satisfaction over my involvements in helping to restore degraded landscapes to a productive, esthetically pleasing condition. Near the end of my presentation I discuss how the growing challenges such as noxious plant invasion, urbanization, climatic change, energy development, endangered species, multiple use conflicts, destructive wildfires, human population increase, and more intensive monitoring needs create opportunities and increased need for range managers. I do mention we have been quite successful in improving rangeland and riparian health nationwide through better grazing management but note that these efforts must be maintained and strengthened.

To cap things off I discuss the various employment opportunities in range management. I emphasize that people who choose a range career have considerable flexibility in where they choose to live and work. International opportunities are good and should get better. At NMSU we have had 100\% employment of our range graduates during the past 6 years. Employer demand for our range graduates exceeds the num- ber of students we have supplied. Generally, starting salaries for our range graduates have exceeded the average for other graduates with majors relating to some aspect of agriculture or natural resource management.

I have found that a 40-45-minute PowerPoint presentation with 30-35 well-chosen slides, followed by a 10-15-minute question-and-answer session works best. It is my observation that high school students tended to lose focus and interest if the presentation was too long, was redundant, or became verbose. Incorporating some of my own life story and personal experiences improved their interest. Slides showing sharp landscape contrasts from different grazing, brush, and riparian management practices have been effective in capturing and holding student attention. Most students seem to find the opportunity to improve landscape health compelling.

\section{Recruiting Effectiveness}

By now I am sure some readers of this article are wondering what the impact of my recruiting efforts have been on undergraduate range enrollment at NMSU. The results are incomplete, but the initial results have been quite encouraging. In spring 2005 I initiated my recruiting efforts by speaking to 6 high school classes. In fall 2005 undergraduate enrollment in the range program at NMSU increased from 36 to 44 students. This inspired me to expand my recruiting efforts to cover 30 high schools during the autumn 2005 through spring 2006 period. The results from these efforts will remain a question until the autumn semester begins at NMSU in late August 2006. Whether or not we receive a major boost in enrollment in the range program at NMSU, I have enjoyed, learned much from, and felt gratified from my recruiting efforts. I most firmly believe that the future of rangelands depends heavily on better informing young people and attracting them into our discipline. The effects of my programs in educating high school teachers may be as or more important than those on students. It quickly became obvious to me that high school teachers can play a major role in furthering range education and encouraging promising students towards range careers.

Author is Professor of Range Science, Department of Animal and Range Sciences, New Mexico State University, Las Cruces, NM 88003, holechek@nmsu.edu. This paper was supported by the New Mexico Agricultural Experiment Station and was part of project 1-5-274170. 